\title{
The Enlistment Medical Examination - Reasons for Failure
}

\author{
D M Sinclair, \\ MB, ChB, MRCGP, Civilian Medical Practitioner \\ The Health Centre, Victoria Road
}

SUMMARY: During 1984 a short summary of all recruits who failed their recruitment medical examination at Leven was kept. An overall failure rate of $19 \%$ was discovered and no recruit examined in 1984 from Army Careers Information Office, Leven, was dismissed from service on medical grounds. It seems quite likely, therefore, that the Regulations covering medical fitness are adequate. Indeed, the Regulations may sometimes exclude fit men from Army service.

\section{Introduction}

It is obvious that servicemen in all three Services need to be fit for their profession. There are medical conditions which, while of little significance in civilian life, can lead to difficulties in service life, particularly when a man is assigned to strenuous duties. Such medical conditions must be detected at the enlistment medical examination or Pre-Service Pulheems Examination.

The enlistment medical should also be cost effective. The cost of one such examination is in the region of 1,000 th the cost of training a soldier.

The "bible" of the Recruit Medical Officer is the Joint Service Publication $346^{1}$ and amendments as distributed by Army Headquarters Edinburgh (in Scotland).

When Civilian Medical Practitioners (CMPs) visit recruit depots they are often told of "lame ducks" who had been passed as fit by them. It is then left to the staff of the depot to discharge the hopeful recruit from the Army. Although mistakes by CMPs must occur, it is important for RAMC Officers to recognize that the vast majority of recruits are skilfully screened at the Army Careers Information Office.

The Army Careers Information Office at Leven is a small three man office covering the whole of East Fife, just north of Edinburgh. The author performs almost all the recruit medical examinations with help from one of his partners when he is on leave.

In 1984, 208 recruits were seen for initial medical examination. 45 potential recruits $(22 \%)$ failed, and seven of these potential recruits $(3 \%)$ passed on reexamination thus giving an overall failure rate of $19 \%$. All those who enlisted have passed through their recruit training without dismissal on medical grounds.

Reasons for Failure (NB - some recruits had more than one reason for failing)

1. Systolic Hypertension: 10 recruits. Two recruits were subsequently accepted, having been seen by Consultant Physicians.

2. Systolic Heart Murmurs: 9 recruits. Two recruits subsequently saw NHS Physicians, had a normal ECG and chest $\mathrm{x}$-ray, and then were re-examined by the author and passed.
3. Orthopaedic/foot problems: 8 recruits. One recruit had a traumatic effusion of his knee at the time of examination, but subsequently passed. He had also been seen by a Consultant Surgeon who passed him as fit. Six other recruits had severely overlying toes and one recruit had chondromalacia patellae.

4. Skin Disorders: 8 recruits. Seven skin disorders included dermatitis, needing systemic or local drug treatment on either a prolonged or intermittent basis There were two cases of psoriasis, one of which was previously undiagnosed.

5. Asthma/Hay Fever/Perennial Rhinitis: 7 recruits There were two frank asthmatics requiring inhaler\$ which they had not declared initially at the Armo Careers Information Office. The others had allergie symptoms requiring regular use of antihistamines.

6. Obesity: 4 recruits. Two reduced their weights te within tolerable limits based on the average weight for their height and age, and were subsequently passed.

7. Underweight: 2 recruits. These recruits were told to "build themselves up" but they did not return.

8. Ear Defects/Deafness: 2 recruits. One had moist perforations, the other an abnormal audiogram. The latter recruit subsequently passed when seen at the Receiving Medical Station by an ENT surgeon.

9. Eyesight / Epilepsy / Enuresis / Proteinura /Emotional Stability/Migraine: One recruit in each category. The potential recruit with proteinura also had systolic hypertension, a systolic heart murmur and a tremor, and was advised to seek his General Practitioner's advice. The author also wrote to the GP to let him know of the results of the examination. The recruit with psychiatric problems had just been under review by a psychiatrist having had a history of self-poisoning.

It can be seen from this admittedly small survey a surprisingly large proportion of potential recruits was deemed medically unfit for the British Army. In my opinion, this was mainly due to the high standards demanded by the Services rather than to the low standards of the recruits.

One recruit required medical attention because of the findings of his examination (proteinura, hypertension, 
heart murmur, tremor) and another because of previously undiagnosed psoriasis.

One recruit who had widespread psoriasis requiring continual drug therapy was very unhappy about his rejection and took his case as far as Parliament. He had not been permitted to enlist at the time of writing.

As far as can be ascertained, there are no figures available from other Army Careers Information Offices. Comparison of such statistics would, however, be interesting.

\section{REFERENCE}

1. JSP 346 Pulheems - A Joint Service System of Medical Classification 1976.

\section{Editorial Note}

Last year there were 36,000 applicants to join the Army. Of these 2,500 were rejected on medical grounds at Army Careers Information Offices (ACI0s). If all those who applied were examined at the outset this gives a rejection rate of $7 \%$. If on the other hand only those $40 \%$ who would otherwise have gone foward to basic training units were medically examined the rate becomes $18 \%$, very close to Dr Sinclair's figures. Presumably the true answer lies somwhere between the two figures, since some medical examinations are undoubtedly carried out on applicants who subsequently withdraw or are found to be unsuitable on other grounds.

During basic training a futher $1 \%$ of the intake is discharged on medical grounds, split as follows:

a. Condition not disclosed at ACIO: $40 \%$

b. Condition brought to light by rigorous training, for example knee or spinal problems: $40 \%$

c. Condition spotted by Medical Officer at ACIO but thought to be "worth a try": $10 \%$

d. Condition overlooked by Medical Officer at $\mathrm{ACI} 0$ $10 \%$. 